\title{
Preparation of future teachers for professional activities in a polycultural educational space
}

\author{
Leviza Abbasova ${ }^{1 *}$ \\ ${ }^{1}$ State Budget Educational Institution of Higher Education of the Republic of Crimea Crimean \\ Engineering and Pedagogical University the name of Fevzi Yakubov, Simferopol, Russia
}

\begin{abstract}
In the system of modern higher education, one of the urgent problems requiring uncompromising effective solutions is that of the professional training of future teachers in a polycultural educational space within which it is possible to form a competitive specialist, an active and conscientious citizen of Russia. Today, the professional training of future teachers in a polycultural educational space is becoming increasingly important as one of the foundations for building interpersonal and social relations. One of the primary directions of reforming the educational process in higher education is implementation of principles of universal human values, the formation of awareness of the interrelation among freedom, human rights and civic responsibility, the ability of interpersonal communication and preparation of the younger generation for life in modern conditions.
\end{abstract}

\section{A problem statement}

Professional competencies are recognized as one of the key competencies, which indicates a serious interest of the state in the training of highly qualified specialists who are able to carry out effective teaching activities in the modern teaching environment.

The concept of "space" (from English "environment" - the surroundings or conditions in which a person, animal, or plant lives or operates) in other social sciences - philosophy, sociology, psychology, social psychology - has been used for a long time. In the broadest sense, "space" is understood as a huge number of objects between which relationships are established. The teacher's professional activity is aimed at a person in the environment, aimed at solving the entire set of problems in the context of "personality and environment".

Taking into account the pecularities of training of future teachers for professional activities in a cultural educational environment, we proceeded from the fact that the natural and social environment is a reality in which human life takes place and which directly participates.

Multicultural educational space is a special reality that exists on the basis of the interaction of many ethnic cultures that are different in their content, but equal in importance and equal in social status. Representatives of ethnic cultures make up the contingent of the educational organization, including higher education.

\footnotetext{
${ }^{*}$ Corresponding author: ipcs-profped@yandex.ru
} 


\subsection{The objective of the work}

To determine the theoretical significance of the problem under consideration, review the literature, and define the key concept of the research, theoretical methods were used: analysis, synthesis, modeling. A pedagogical experiment was chosen as the leading research method in order to reveal the effectiveness of the proposed pedagogical conditions in preparing future teachers for professional activity in a polycultural educational space.

\section{Materials and the results of the research}

Professional training of future teachers in a polycultural educational space provides the opportunity to learn the culture of different nations, thereby creating the preconditions for mutual understanding and respect, positions of cooperation, which is the key to social and interethnic stability. The basis of the modern educational space should be a polycultural environment, which provides a change in the system of human relations built on mutual respect. In order to successfully perform a range of professionally significant tasks, a teacher must not only master knowledge, skills and abilities, but also have personal and professional qualities.

The analysis of literary sources shows that understanding the environment is associated with the category of space, which was formed mainly in the natural and physical and mathematical sciences on the basis of observation and practical determination of the position of objects in their relation to each other, as well as comparison of their volume and length.

In the context of the problem of multicultural education, one of the important issues is the training of teachers who are able to carry out professional and pedagogical activities in educational institutions with a multinational composition of students [1]. The problems of the formation of professional competence of various specialists are considered in the works of N.A. Gluzman [2], I.A. Winter [3], Fakhrutdinova G.Zh. [4], Logan Rutten [5], Mariana Sirotová [6].

Contents and ways of forming the following issues are studied: the culture of interethnic relations of student youth in higher educational establishments (N.V. Gorbunova [7], D.S. Batarchuk [8], V. Popova [9]), the culture of interethnic communication (N.G. Markova [10]), ethno cultural competence (A.B. Afanasyeva [11], Paola Dusi), readiness of teachers for professional activity in a multicultural environment (Manuel José López Martínez [13], M.A. Dana Likeschová [14], Yu.V. Kashina [15]).

N.U. Yarychev [16] believes that the policultural educational environment as a set of conditions for the implementation of the educational process is a necessary, objectively existing condition in the context of the formation of tolerance of the subjects of the educational process. The effectiveness of this process increases if its potential is actualized for the formation of a responsible, tolerant personality, capable of successfully organizing its activities in problem situations, possessing professional and linguo-socio-cultural competence, moral consciousness, creative, capable of constructively adapting in a diverse and multicultural world. A.I. Bogdanova characterizes the policultural educational environment as an environment that "promotes understanding of the values of universal, national and individual culture by multicultural individuals within the environment itself and contributes to the adaptation of the individual to culture through education" [17].

Successful professional training of future teachers of an educational organization can be effectively implemented under pedagogical conditions of the model of professional training of future teachers in a polycultural educational space, if: a polycultural educational environment is created as a factor of formation of ethnic tolerance among future teachers; the formation of positive attitudes among students towards themselves and the people 
around them is being experienced; the moral potential of future teachers is being icreased; the use of interactive technologies in a multicultural space in the professional training of future teachers is being applied.

The results of the experimental work showed that if the pedagogical terms are observed, future teachers in educational organizations have an increased desire to develop professional competence and effective relationship with other people which includes such value characteristics of a professional as respect, acceptance and correct understanding of the rich variety of forms of self-expression and ways of manifestation of human individuality, and also acts as the inner core of socio-psychological being, determining a person's attitude to himself and to the world around him and recognizing the authenticity and individuality of other participants in pedagogical activity. The article substantiates methodological approaches to the process of professional training of future teachers in a polycultural educational space; the essence and structure of the concept of "professional training", "professional competence", "multicultural educational space" and the related categorical-conceptual apparatus are revealed; pedagogical conditions and implementation of the model of training future teachers for professional activity in a multicultural educational space are presented.

The following social, demographic and ethnic processes play an important role in adjusting the characteristics of the process of preparing for professional activity in a polycultural environment of future teachers:

- a significant increase in the share of migrants from near and far abroad, especially foreign students;

- changes in the social structure of modern society, the ratio of various ethnic and age groups, the continuing social stratification of the population;

- the growth of ethnocentric sentiments in the student environment, expressed in the real functioning of numerous national student societies, in the advancement of demands from various national groups, and in the presentation of mutual claims by representatives of ethnic groups.

In turn, modern educational institutions of higher education are undergoing significant social transformations, affecting the features of the training of future teachers in general, and the process of forming their professional competence in a polycultural space, in particular:

- strengthening the national component in the content of social and pedagogical education, supporting national traditions among the ethnic groups, studying national history, cultivating national ideals;

- an increase in religious influence on the upbringing process in the educational organization of higher education through various forms of religious education, the content of education in secondary and general education schools, educational institutions of higher education, various forms of additional education;

- state program for the development of ideas of national education (children, youth, family), which, in turn, also affected university education, which is natural;

- implementation of special programs in the field of civil, patriotic, international education, which create an open civil society;

- mutual influence of ethno-cultural, national, state, global aspects of education.

A theoretical analysis of the problem of training future teachers in the process of professional training allowed us to highlight the following features: the value of personality and culture, a personality-oriented approach, tolerance in relations between the subjects of the educational process, a harmonious combination of universal values with national and regional ones. It should be noted that the changes that are taking place in the educational system of Russia affect the nature and characteristics of the process of preparing future teachers for professional activity in a multicultural space, and also in a certain way 
determine the process of preparing specialists for work in the conditions of a polycultural modern society.

The dynamics of the readiness levels of future teachers for professional activity in a polycultural educational space is shown in Figure 1.

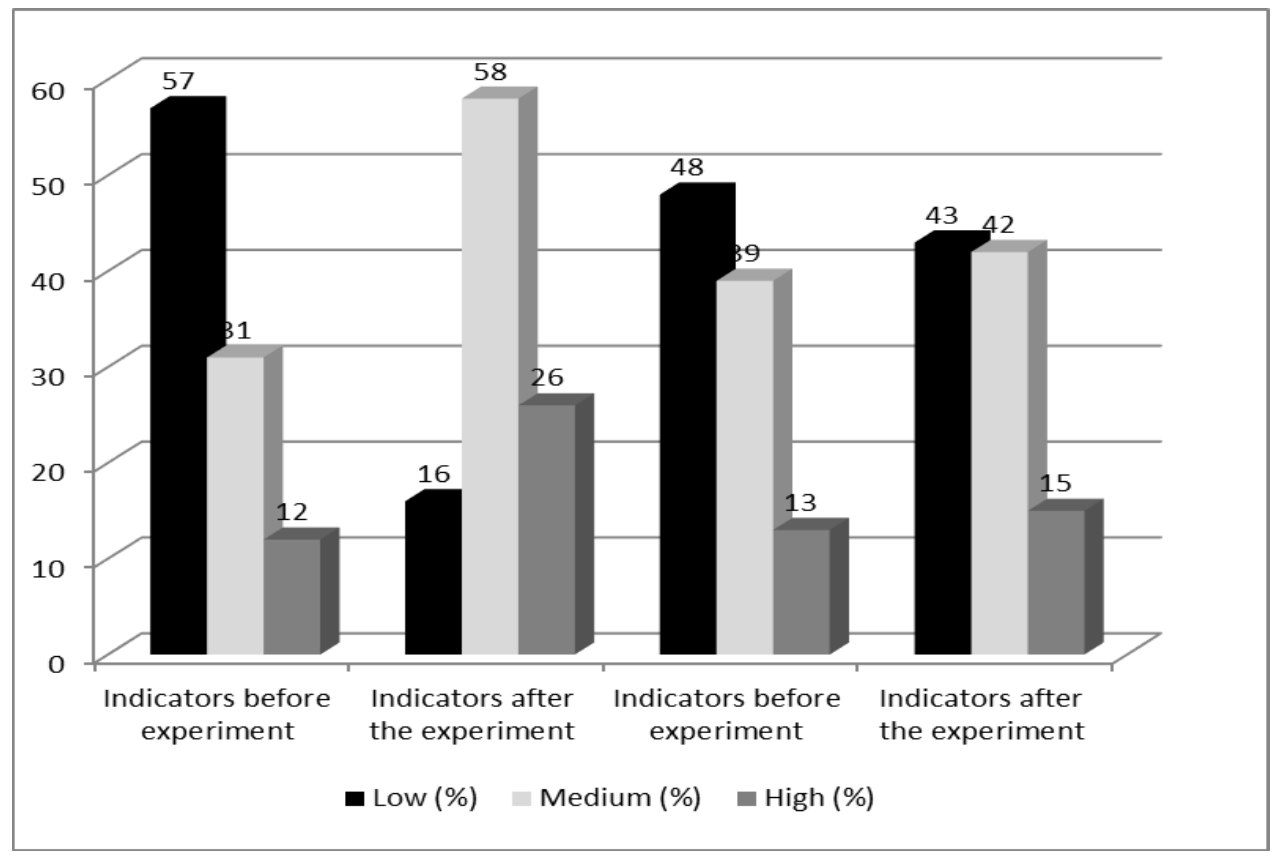

Fig. 1 Comparative results of the levels of readiness of future teachers for professional activity in a polycultural educational space.

Comparative quantitative results presented in fig. 1 indicate a positive trend in the training of future teachers. So, at the ascertaining stage of the experiment, a high level of readiness was observed in $12 \%$ of the respondents in the experimental group, and after the formative experiment their number increased to $26 \%$. There was an increase in the number of students with an average level of readiness of future teachers for professional activity from $32 \%$ at the stage of ascertaining to $58 \%$ at the control stage. The percentage of future teachers with an initially low level of readiness of future teachers for professional activity has decreased from $57 \%$ to $16 \%$.

Less significant changes occurred among the respondents in the control group: the number of respondents who were at the high level increased from $13 \%$ to $15 \%$, at the average one - from $58 \%$ to $42 \%$, and at the low level their quantity decreased from $48 \%$ to $43 \%$.

After the implementation of the pedagogical conditions and the model of training future teachers of the experimental group, they demonstrated the dynamics of positive changes in terms of such indicators as the presence of a stable interest in professional activity in a polycultural educational space, awareness of the need for interethnic communication, reflection of professional actions, the ability to communicate tolerantly. Analyzing the results obtained, one can see that future teachers mastered the norms and rules of tolerant intercultural interaction, the skills of reflection and self-esteem, realized the traits of a tolerant personality, formed positive attitudes towards themselves and other people, the ability to choose strategies for the optimal resolution of conflict and contradictory situations, use interactive technologies in professional activities in a multicultural educational space. 


\section{Conclusions}

The study allows us to assert that the problem of preparing future teachers for the professional activity in the polycultural educational space of pedagogical skills is generally of great interest to the Russian academic community, primarily, in the context of its formation in the process of professionalization of teachers.

The obtained data allowed us to conclude that professional activity, as a professionally important quality of future teachers, was formed spontaneously, since there is no purposeful program for its development, which confirms the need to implement a model for preparing future teachers for professional activity in a polycultural educational space. The implementation of the structural and functional model of the training of future teachers for professional activity took place in several stages: preparatory and familiarization stage, practice and activity stage and reflexive stage.

The effectiveness of the implementation of structural and functional model of the training of future teachers for professional activity in a polycultural educational space is evidenced by the increased interest in the problem of intercultural relations, interest in the culture of interethnic communication, obtaining the norms and rules of tolerant interaction, the skills of reflection and self-esteem, as well as the presence of positive attitudes towards oneself and other people, the ability to choose strategies for the optimal resolution of conflict and contradictory situations, to use interactive technologies in professional activities.

\section{References}

1. A. Dzhurinskiy, School Policy in Russia and the Challenges of A Multicultural Society, 811-814 (2015)

2. N.A. Gluzman, N.V. Gorbunova, Teacher's professionalism. Success and career, 311 (monograph, 2019)

3. I.A. Zimnyaya, Key competencies: new paradigm of educational outcome, 34-42 (2003)

4. G.Zh. Fakhrutdinova, Polycultural education of future teachers, 267-269 (2016)

5. L. Rutten, Toward a theory of action for practitioner inquiry as professional development in preservice teacher education, 103-194(2020)

6. M. Sirotová, Pedagogical Praxis as a Process of Developing Professional Competencies in University Education of Future Teachers, 529-534 (2016)

7. N.V. Gorbunova, Youth policy in the context of Crimea's integration into the sociocultural space of Russia, 32-35 (2019)

8. D.S. Batarchuk The Problem of Interethnic Youth Relations in Multiethnic Educational Environment, 1589-1592 (2017)

9. V. Popova, D. Brinkmana, Harm J.A. Biemansa, M. Muldera, A. Kuznetsov, O. Noroozia, Multicultural student group work in higher education: An explorative case study on challenges as perceived by students, 302-317 (2012)

10. N.G. Markova, Culture of interethnic communication as a basic indicator of interethnic relations, 94-103 (2008)

11. A.B. Afanasyeva, Formation of ethnocultural competence in the system of higher pedagogical education, 77-78 (2007)

12. P. Dusi, G. Messetti, M. Steinbach, Skills, Attitudes, Relational Abilities \& Reflexivity: Competences for a Multicultural Society, 538-547 (2014) 
13. M. José, L. Martínez, The Social and Emotional Competences in the Earliest Academic Training of Compulsory Education Teachers within Multicultural Contexts, 549-556 (2014)

14. M.A. Dana Likeschova, T. Assoc, Multicultural Education, Creativity and Innovation at Universities in the Czech Republic, 349-355 (2013)

15. Yu.V. Kashina, V.A. Vishnevsky, M.A. Vaskov, N.V. Gorbunova, G.V. Ganshina, L.I. Abbasova, Assessment of regulatory-adaptive possibilities of students to the study load at a higher education institution in the conditions of a polycultural educational space, 924-938 (2020)

16. N.U. Yarychev, Polycultural educational environment as an element of the formation of student tolerance, 30-33 (2016)

17. A.I. Bogdanova, Polycultural educational environment, 113-115 (2011) 